\title{
Surgical Treatment of Thoracic Myelopathy Secondary to Ossification of Ligamentum Flavum
}

\author{
Rajnish K. Arora ${ }^{1}$ Manish Jaiswal ${ }^{2}$ Radhey S. Mittal ${ }^{3}$ Poonam Arora ${ }^{4,5}$ \\ ${ }^{1}$ Department of Neurosurgery, All India Institute of Medical Sciences, \\ Rishikesh, Uttarakhand, India \\ 2 Department of Neurosurgery, King George Medical University, \\ Lucknow, Uttar Pradesh, India \\ ${ }^{3}$ Department of Neurosurgery, Sawai Man Singh Medical College, \\ Jaipur, Rajasthan, India \\ ${ }^{4}$ Department of Anesthesiology, SMS Medical College, Jaipur, \\ Rajasthan, India \\ ${ }^{5}$ Department of Anaesthesiology, HIMS, Jolly Grant, Dehradun, \\ Uttarakhand, India \\ Indian J Neurosurg 2016;5:75-83. \\ Address for correspondence Dr. Rajnish K. Arora, MCh, Department \\ of Neurosurgery, All India Institute of Medical Sciences, Virbhadra \\ Marg, Rishikesh, Uttarakhand 249201, India \\ (e-mail: rajnish_19@yahoo.com).
}

\begin{abstract}
Keywords

- ossification of ligamentum flavum

- surgical treatment

- prognostic factors

Objectives We retrospectively studied the risk factors, clinical manifestations, radiological aspects, surgical treatment, and prognostic factors in 143 patients of thoracic ossification of ligamentum flavum (OLF).

Methods A total of 143 patients who underwent surgical treatment for thoracic myelopathy secondary to OLF between 1989 and 2010 were studied retrospectively. Preoperative and postoperative neurological data were reviewed and the correlation between the variables of patient characteristics, preoperative duration of symptoms, preoperative neurological status, and the functional outcome were analyzed. The male to female ratio was $1.5: 1$. In total, 114 patients $(79.72 \%)$ were in the 4 th to 6 th decade of life. Only two cases (1.4\%) were of less than 20-year age group. The lower thoracic region (D9-D12) was most commonly affected (61.5\%). Four patients had long segment involvement ( $\geq 7$ levels) and eight patients had two separate levels of involvement. Associated fluorosis was observed in 32 patients (22.37\%). All patients underwent wide decompressive laminectomy with medial one-third facetectomy and OLF was resected. The part of dura adherent to OLF or calcified is also removed with it and duroplasty done if required. The average follow-up was 5 years.

Outcome In all, 86 patients (60.13\%) were able to do their job with mild neurological deficit such as spasticity and impairment of joint position sense. Twenty-eight patients (19.58\%) were back to some job with limitation but were independent for their routine work. Sixteen patients (11.18\%) improved but still required help for their routine work while thirteen patients (9.09\%) were bed-ridden at last follow-up. Most common complications observed were cerebrospinal fluid leak (7.69\%), neurological deterioration (8.39\%), and infection (4.89\%). Five (3.4\%) patients required second surgery for ossification at other level during follow-up.
\end{abstract}

received

April 24, 2016

accepted

July 29, 2016

published online

August 25, 2016
DOI http://dx.doi.org/

10.1055/s-0036-1592099. ISSN 2277-954X. (c) 2016 Neurological Surgeons' Society of India
License terms

(ㄷ) (i) $\ominus$ (\$) 
Ossification of ligamentum flavum (OLF), though rare, is being increasingly recognized as a cause of thoracic myelopathy. Earlier, OLF has been reported almost exclusively in East Asian countries, particularly in Japan and Korea. Studies of OLF from other regions, such as India, ${ }^{1-5}$ Middle East, ${ }^{6}$ and West including Caribbean, ${ }^{7-9}$ are increasingly being reported. This is one of the largest study reported, so far, in literature. Adults in the age group of 30 to 60 years are affected most frequently, and the disease has a strong predilection for the lower thoracic spine (T9-T12). Because of the low prevalence of this disorder, small patient population, and the rarity of large clinical reports, the treatment guidelines and surgical prognosis in patients with this disease remain unclear. In the present study, we retrospectively analyzed the clinical features of patients with symptomatic thoracic OLF treated surgically at our institute.

\section{Clinical Materials and Methods}

Data were collected from medical records to define the preoperative clinical features of OLF myelopathy patients including age and sex, signs and symptoms, and duration of symptoms. Neurological status was assessed preoperatively and postoperatively and surgical outcome was determined after the OLF surgery. We used Nurick system ${ }^{10}$ for evaluation of patients. We evaluated the correlation between outcome and age, gender, level and number of segments affected by OLF, preoperative duration of symptoms, preoperative neurological status, radiological findings, and the presence of dural adhesions observed intraoperatively.

\section{Patient Characteristics}

One hundred and forty-three patients with thoracic OLF underwent surgery between 1989 and 2010 for the treatment of thoracic OLF in our institution. There were 87 male and 56 female patients who ranged in age from 15 to 78 years (mean, 45 years). The symptoms had been present for few weeks to 4 years prior to treatment. A total of 101 patients (70.6\%) had duration of symptoms $\geq 1$ year. A majority of our patients (79.02\%) were able to walk only with assistance or were

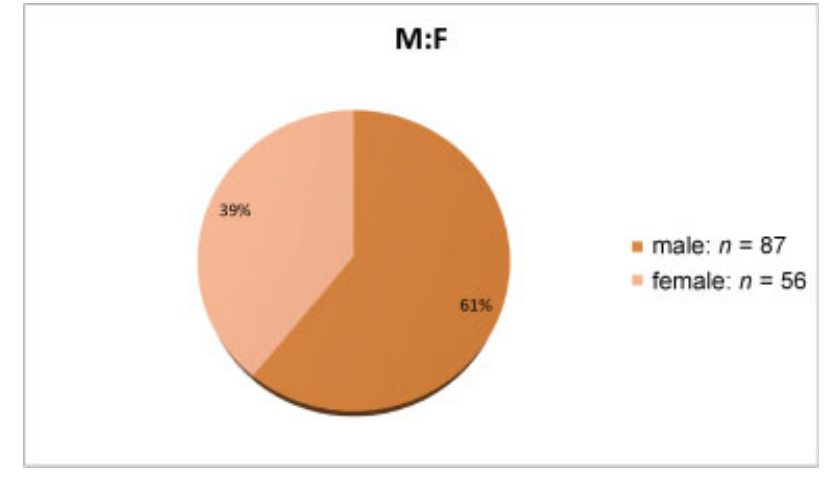

Fig. 2 Sex ratio of patients.

wheel chair-bound/bed-ridden (Nurick grade 4 and 5) indicating advanced disease at presentation. The diagnosis was established after thorough neurological examination and subsequent imaging studies including myelogram, computed tomography (CT), and magnetic resonance imaging (MRI). All patients were evaluated and underwent surgical intervention. The postoperative follow-up duration ranged from 12 months to 18 years (mean, 60 months).

Demographics of patients are shown in -Figs. 1 and 2. Nearly $80 \%$ of patients were in the age group of 30 and 60 years which is the most commonly affected age group. Most common presenting symptoms included difficulty in walking (97\%), numbness (93\%), backache (85\%), and urinary disturbances in 78 (54.54\%) patients. Spasticity and lower limb weakness was present in nearly all patients ( $>97 \%$ ). Two patients had hypotonia. ( - Table 1 ) The lesions characteristics of patient are shown in -Fig. 3, - Table 2, and - Figs. 4-6.

\section{Imaging}

Because of unavailability of MRI at our center during initial period, myelogram was performed in 24 patients and CT alone was done in 2 cases. MRI study of whole spine was performed in 117 patients (81.8\%) with or without CT scans. Cord hyperintensities on $\mathrm{T} 2$ images were present in 33 patients preoperatively.

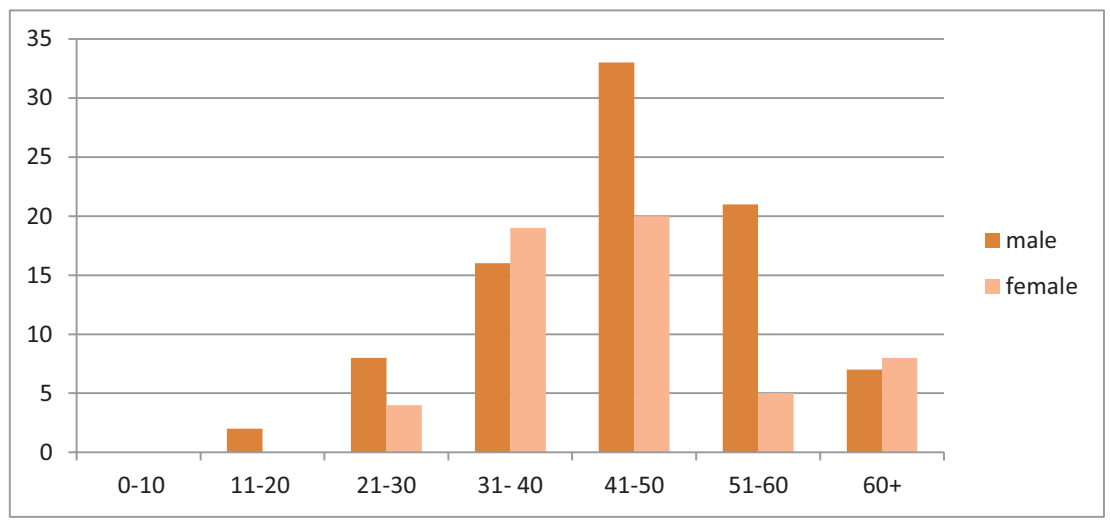

Fig. 1 Age distribution: $X$ axis represents age groups and number of patients is represented along $Y$ axis. 
Table 1 Clinical characteristics

\begin{tabular}{|c|c|c|}
\hline & $\begin{array}{l}\text { No. of } \\
\text { patients }\end{array}$ & Percentage (\%) \\
\hline \multicolumn{3}{|l|}{ Symptoms } \\
\hline Walking difficulty & 139 & 97.20 \\
\hline Numbness of lower limbs & 134 & 93.70 \\
\hline Backache & 122 & 85.31 \\
\hline Sphincter disturbance & 78 & 54.54 \\
\hline \multicolumn{3}{|l|}{ Signs } \\
\hline Spasticity & 141 & 98.6 \\
\hline Hypotonia & 2 & 1.39 \\
\hline Paraparesis/paraplegia & 139 & 97.20 \\
\hline Sensory disturbance & 135 & 94.40 \\
\hline Sphincter disturbances & 78 & 54.54 \\
\hline
\end{tabular}

\section{Surgical Procedure}

Surgical treatment is indicated for symptomatic OLF. The goal of surgical treatment was a complete cord as well as nerve root decompression at the involved level, and a decompressive laminectomy and resection of the OLF was performed in all cases. We used drill for performing the laminectomy and thinning of OLF. The range of laminectomy included one lamina superior and inferior to the diseased segments in addition to the medial one-third facetectomy through the diseased segment. If ossified dura mater was present, it was resected trying to preserve the arachnoid mater (-Fig. 7). If cerebrospinal fluid (CSF) leakage was found, the dura mater was repaired. Five patients underwent second surgery for symptomatic OLF at other levels later. No fusion was performed in any of our patients. We not only decompress the cord, but also look for nerve roots in intervertebral foramina and if needed, they were decompressed also.

\section{Results}

\section{Post-op Evaluation}

We evaluated our patients using Nurick system ${ }^{10}$ ( - Table 3 ). Eighty-six patients (60.13\%) were able to do their job with

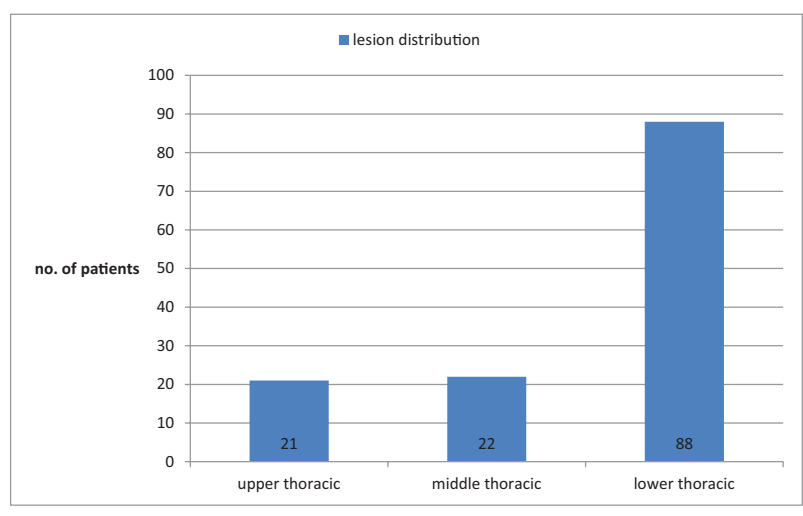

Fig. 3 Shows lesion distribution in thoracic spine.
Table 2 Lesion characteristics

\begin{tabular}{|l|l|l|}
\hline Level of involvement & $\begin{array}{l}\text { No. of } \\
\text { patients }\end{array}$ & $\begin{array}{l}\text { Percentage } \\
\text { (\%) }\end{array}$ \\
\hline $\begin{array}{l}\text { Long segment involvement } \\
\text { (laminectomy } \geq 7 \text { levels) }\end{array}$ & 4 & 2.8 \\
\hline Two separate levels & 8 & 5.6 \\
\hline $\begin{array}{l}\text { Concomitant } \\
\text { cervical + dorsal involvement }\end{array}$ & 21 & 14.68 \\
\hline $\begin{array}{l}\text { Concomitant } \\
\text { dorsal }+ \text { lumbar involvement }\end{array}$ & 44 & 30.76 \\
\hline
\end{tabular}

${ }^{a}$ Note the significant number of patients with coexisting cervical and lumbar ligamentum flavum along with the thoracic involvement. This makes evaluation of whole spine necessary in a case with symptomatic ligamentum flavum of one region of spine.

mild neurological deficit such as spasticity and impairment of joint position sense. Twenty-eight patients (19.58\%) were back to some job with limitation but were independent for their routine work. Sixteen patients (11.18\%) improved but still need help for their routine work while thirteen patients (9.09\%) were bed-ridden at last follow-up. (-Table 4 ).

\section{Complications}

Postoperatively, seven cases (4.89\%) had infection and eleven cases (7.69\%) had CSF leak. Twelve (8.39\%) cases deteriorated neurologically. Five (3.4\%) cases required second surgery for ossification at other level during follow-up. The mean follow-up was 5 years. Statistical analysis was done using chi-square test and an odds ratio (OR) was calculated.

\section{Prognostic Factors}

We evaluated the relationship of various preoperative parameters with surgical outcomes (good outcome as postoperative Nurick grade $\leq 3$ and poor as Nurick grade 4-5) and found that out of these only the short duration of symptoms and preoperative neurological status reached statistical significant value (-Table 5). There was no relation of sex, age, level of OLF, number of OLF affected segments, and type of OLF with surgical outcome. But we believe that the following factors were also important in predicting the surgical outcome, though not reaching a statistically significant value: degree of spinal cord compression, absence of proximal stenosis, intramedullary hyperintensity on T2 images, intraoperative cord manipulations, and degree of decompression achieved.

\section{Discussion}

OLF is no longer a condition seen only in East Asia, but is present worldwide. Still it is a relatively rare entity with unknown origin, insufficient epidemiological data, and no guidelines or standards for its treatment. The ligamentum flavum is a yellow elastic ligament extending from the second cervical vertebra to first piece of sacrum. The ligamentum flavum bilaterally has two components, medially interlaminar portion and laterally capsular portion. ${ }^{5}$ It is believed that the hypertrophy of ligamentum flavum precedes the development 


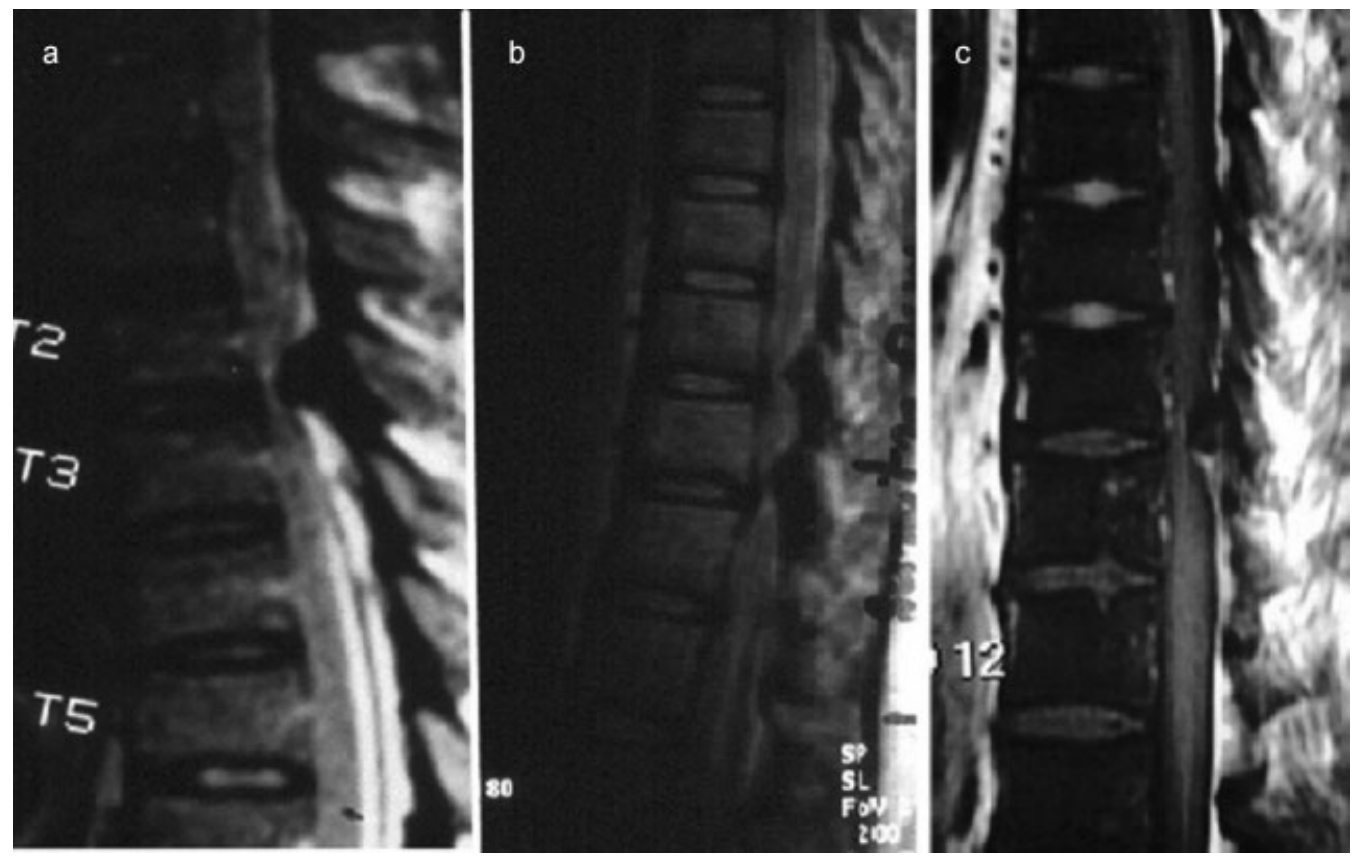

Fig. 4 (a-c) Magnetic resonance appearance of ligamentum flavum showing hypointense excrescences into spinal canal projecting from posterior aspect. (a) Upper thoracic ligamentum flavum, showing round type morphology, (b) middle thoracic ligamentum flavum, showing a beak type morphology, and (c) lower thoracic, which is the commonest site of involvement by ligamentum flavum.

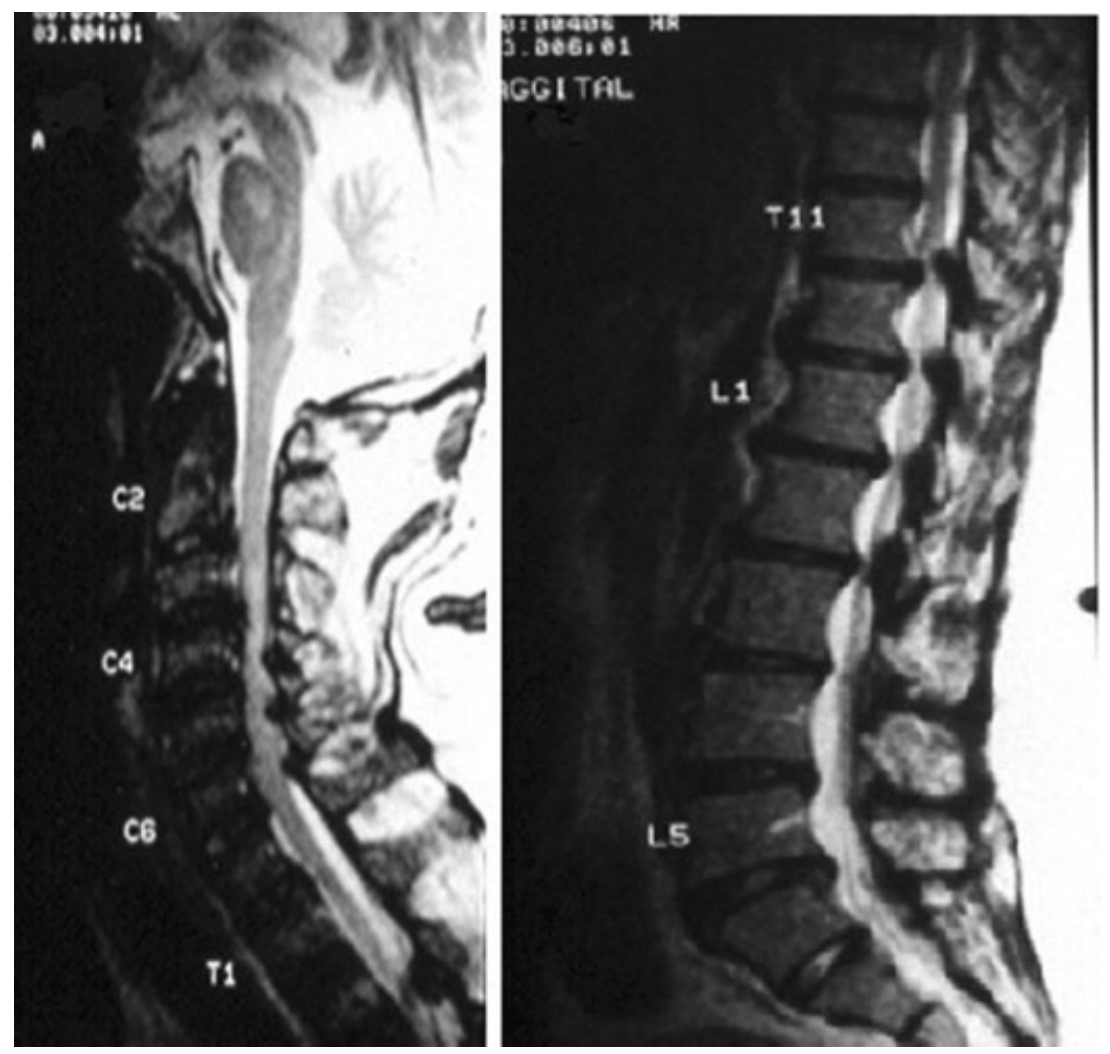

Fig. 5 Sagittal T2-magnetic resonance images showing concomitant involvement of lumbar (a) and cervical spine (b) along with thoracic ligamentum flavum-this is a common finding emphasizing the fact that whole spine examination is necessary in patients with ligamentum flavum of one region of spine.

of OLF. The early ossification is usually found on capsular side of ligament in front of the facet joints. Then it expands on the outer surface of ligament anteriorly toward the spinal cord gradually giving rise to two paramedian nodules within the spinal canal that compresses the posterior portion of the spinal cord (-Fig. 6a-d). Rarely, the lateral capsular outgrowth impinges on an existing nerve root resulting in foraminal stenosis and radiculopathy. Both masses are usually connected 


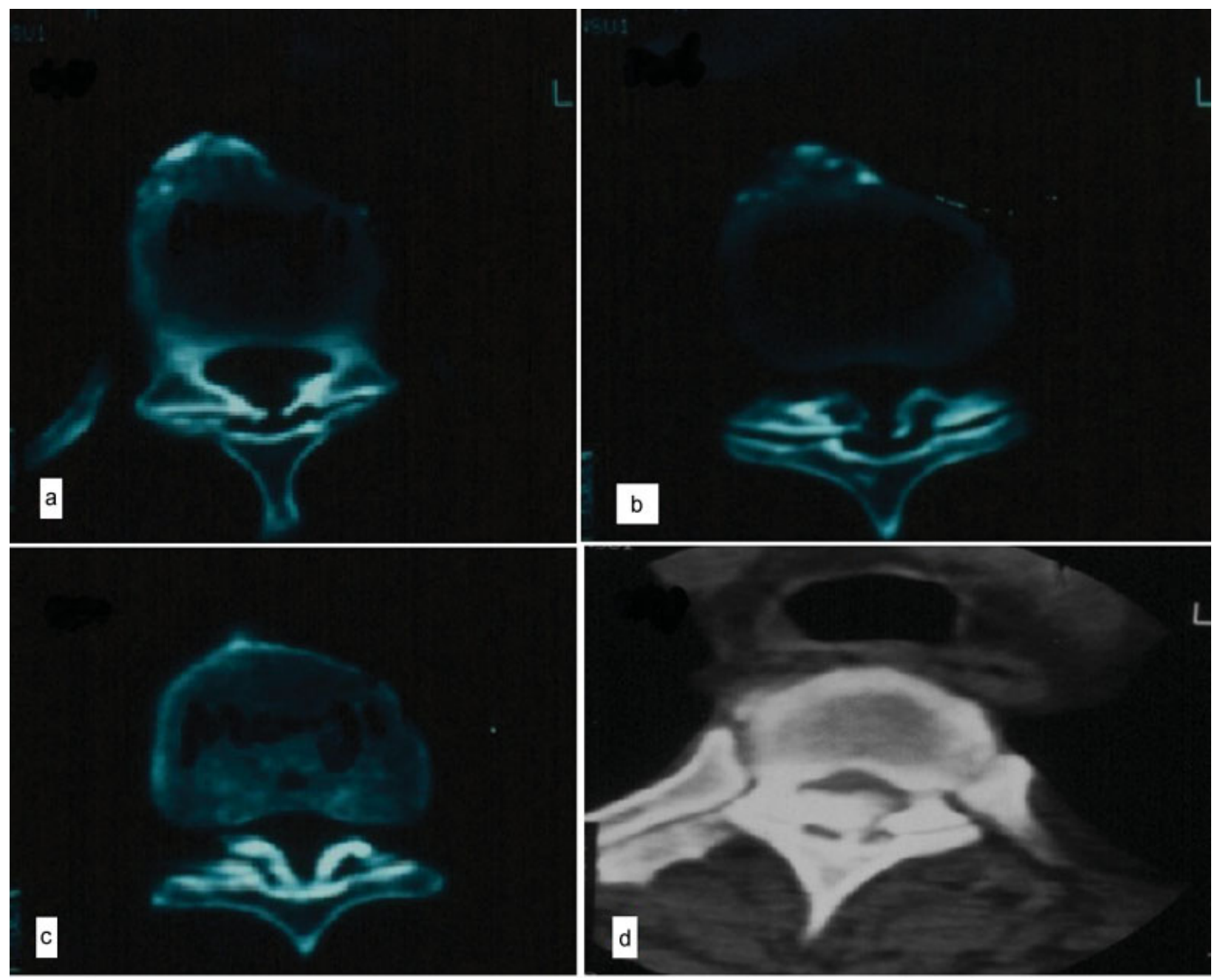

Fig. 6 (a-d) Different types of ligamentum flavum on axial computed tomography: appearing as hyperdense nodules projecting into the spinal canal. (a) Lateral type, (b) enlarged type, (c) fused type, and (d) tuberous type.

by a film of elastic fibers which subsequently also ossifies on its epidural surface and occupies the spinal canal in the form of a central mass. This further contributes to cord compression as it

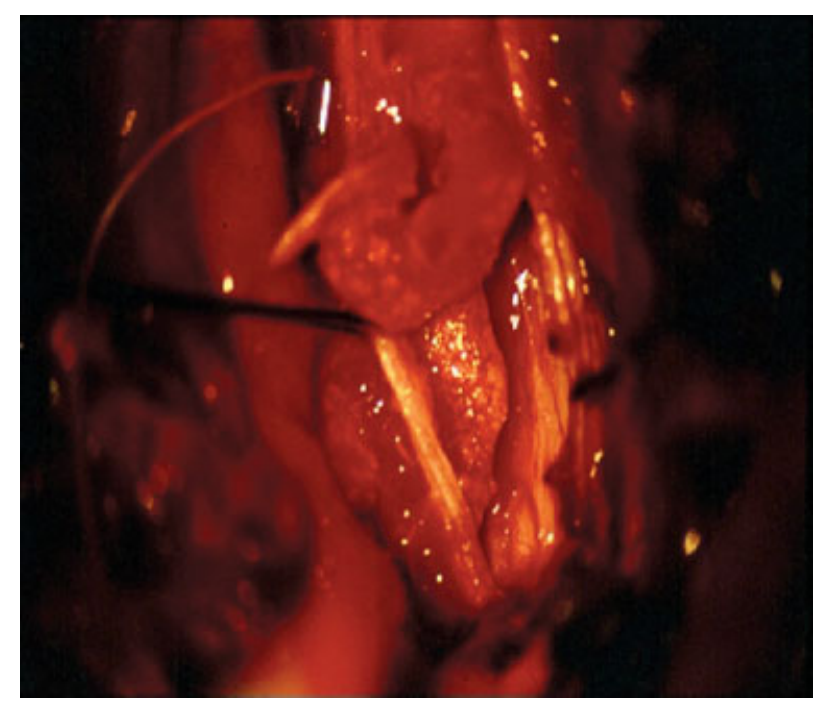

Fig. 7 Intraoperative photograph showing the dural calcification in a case of ligamentum flavum. thickens and extends in a caudocranial direction along the posterior border of spinal canal in a linear fashion as a beak-like outgrowth. $^{3}$ OLF is the result of a metaplastic process in which enchondral ossification leads to lamellar bone formation ${ }^{12,13}$ (-Fig. 8) It is reported to occur most commonly in thoracic, then lumbar, and rarely in cervical spine. ${ }^{14}$ ( $\mathbf{- F i g . ~ 5 a , ~ b ) ~}$

Thoracic OLF most commonly involves the lower thoracic spine vertebrae between $\mathrm{T} 9$ to $\mathrm{T} 12^{13,15-17}$ where greater mobility and vulnerability (due to spinal motion) may result in frequent mechanical injury along with a unique orientation of zygapophyseal joints that contribute to increased rotatory instability and micro mobility. ${ }^{18}$ In the present study, a similar distribution was observed. OLF can occur in upper and mid thoracic level, (- Fig. 4 a-c) and causes can be multifactorial. Mechanical stress involving constraints on the articular processes during rotation might be a critical factor. ${ }^{17}$ The elastic fiber breakdown and increase in the number of collagen fiber in ligamentum flavum has been reported to exhibit increased affinity for calcium and promote the formation of calcium deposits, chondrometaplasia, and enchondral ossification. The factors released during repair of damaged ligament from mechanical stress for example, fibronectin, ${ }^{19}$ bone morphogenic protein ${ }^{20}$ and transforming growth 
80 Surgical Treatment of Ossified Ligamentum Flavum Arora et al.

Table 3 Nurick grades

\begin{tabular}{|l|l|}
\hline Grade 0 & Root signs and symptoms, no sign of spinal cord involvement \\
\hline Grade 1 & Signs of spinal cord involvement, but no difficulty walking \\
\hline Grade 2 & Slight difficulty walking, which does not prevent full-time employment \\
\hline Grade 3 & Gait abnormality prevents full employment, but doesn't require someone else's help for walking \\
\hline Grade 4 & Able to walk only with assistance/walker \\
\hline Grade 5 & Chair-bound or bed-ridden \\
\hline
\end{tabular}

Table 4 Outcome

\begin{tabular}{|l|l|l|}
\hline Outcome & No. of patients & Percentage (\%) \\
\hline $\begin{array}{l}\text { Good: } \\
\text { Improvement by } \geq 3 \text { grades } \\
\text { Nurick grade at last follow-up 0-2 }\end{array}$ & 86 & 60.13 \\
\hline $\begin{array}{l}\text { Fair: } \\
\text { Improvement by } 2 \text { grades/Nurick grade at last follow-up 3 }\end{array}$ & 28 & 19.58 \\
\hline $\begin{array}{l}\text { Improved: } \\
\text { Improvement by } 1 \text { grade/Nurick grade at last follow-up 4 }\end{array}$ & 16 & 11.18 \\
\hline $\begin{array}{l}\text { Poor: } \\
\text { no Improvement/neurological deterioration } \\
\text { Nurick grade at last follow-up 5 }\end{array}$ & 13 & 9.09 \\
\hline
\end{tabular}

Table 5 Correlation between preoperative features with surgical outcome

\begin{tabular}{|c|c|c|c|c|c|c|c|c|}
\hline \multicolumn{2}{|l|}{ Parameter } & \multirow{3}{*}{$\begin{array}{l}\text { No. of patients } \\
128\end{array}$} & \multicolumn{2}{|c|}{$\begin{array}{l}\text { Functional } \\
\text { outcome }\end{array}$} & \multirow{4}{*}{$\begin{array}{l}x^{2} \\
\text { test } \\
0.423\end{array}$} & \multirow{4}{*}{$\begin{array}{l}p \\
0.52\end{array}$} & \multirow{4}{*}{$\begin{array}{l}\text { OR } \\
(95 \% \mathrm{CI}) \\
1.498 \\
(0.440-5.100)\end{array}$} & \multirow{4}{*}{$\begin{array}{l}p \\
0.52\end{array}$} \\
\hline & & & Good & Poor & & & & \\
\hline \multirow[t]{2}{*}{ Age } & $\leq 60$ & & 103 & 25 & & & & \\
\hline & $>60$ & 15 & 11 & 4 & & & & \\
\hline \multirow[t]{2}{*}{ Sex } & Male & 87 & 67 & 20 & \multirow[t]{2}{*}{1.008} & \multirow[t]{2}{*}{0.31} & \multirow{2}{*}{$\begin{array}{l}0.641 \\
(0.269-1.532)\end{array}$} & \multirow[t]{2}{*}{0.32} \\
\hline & Female & 56 & 47 & 9 & & & & \\
\hline \multirow[t]{2}{*}{ Levels involved } & $<4$ & 110 & 87 & 23 & \multirow[t]{2}{*}{0.117} & \multirow[t]{2}{*}{0.73} & \multirow{2}{*}{$\begin{array}{l}0.841 \\
(0.310-2.278)\end{array}$} & \multirow[t]{2}{*}{0.73} \\
\hline & $\geq 4$ & 33 & 27 & 6 & & & & \\
\hline \multirow[t]{2}{*}{ Pre-op duration of symptoms } & $<1$ year & 42 & 38 & 4 & \multirow[t]{2}{*}{4.255} & \multirow[t]{2}{*}{$0.039^{\mathrm{a}}$} & \multirow{2}{*}{$\begin{array}{l}3.125 \\
(1.015-9.626)\end{array}$} & \multirow[t]{2}{*}{$0.047^{\mathrm{a}}$} \\
\hline & $\geq 1$ year & 101 & 76 & 25 & & & & \\
\hline \multirow{2}{*}{$\begin{array}{l}\text { Cordhyper intensity } \\
(n=117)\end{array}$} & Present & 33 & 25 & 8 & \multirow[t]{2}{*}{2.164} & \multirow[t]{2}{*}{0.14} & \multirow{2}{*}{$\begin{array}{l}0.471 \\
(0.170-1.303)\end{array}$} & \multirow[t]{2}{*}{0.12} \\
\hline & Absent & 84 & 73 & 11 & & & & \\
\hline \multirow[t]{2}{*}{ Dural adhesions } & Present & 83 & 65 & 18 & \multirow[t]{2}{*}{0.242} & \multirow[t]{2}{*}{0.62} & \multirow{2}{*}{$\begin{array}{l}0.811 \\
(0.351-1.872)\end{array}$} & \multirow[t]{2}{*}{0.62} \\
\hline & Absent & 60 & 49 & 11 & & & & \\
\hline \multirow[t]{2}{*}{ Pre-op Nurick grade } & $\leq 3$ & 30 & 28 & 2 & \multirow[t]{2}{*}{4.352} & \multirow[t]{2}{*}{$0.037^{\mathrm{a}}$} & \multirow{2}{*}{$\begin{array}{l}4.395 \\
(0.982-19.665)\end{array}$} & $0.043^{a}$ \\
\hline & $4-5$ & 113 & 86 & 27 & & & & \\
\hline
\end{tabular}

${ }^{a}$ Shows statistically significant values.

factor- $\beta^{21,22}$ may play a role in genesis of OLF. OLF is frequently associated with narrowing of neural canal, ossification of the posterior longitudinal ligament, or ossification of other ligaments and symptomatic thoracic disc herniations. A high incidence of coexisting spinal disorders in patients with thoracic OLF makes the examination of whole spine necessary. $^{23}$
It has been documented that incidence of thoracic OLF is higher in the patients with diffuse idiopathic skeletal hyperostosis, ${ }^{24}$ fluorosis, ${ }^{2,25,26}$ diabetes, ${ }^{27}$ and ankylosing spondylosis. In our study, fluorosis was found in 32 (22.37\%) patients, which can be correlated as an etiological factor in pathogenesis of OLF. It is reported that flouride (F) can activate intracellular c-AMP, causing a significant increase of 


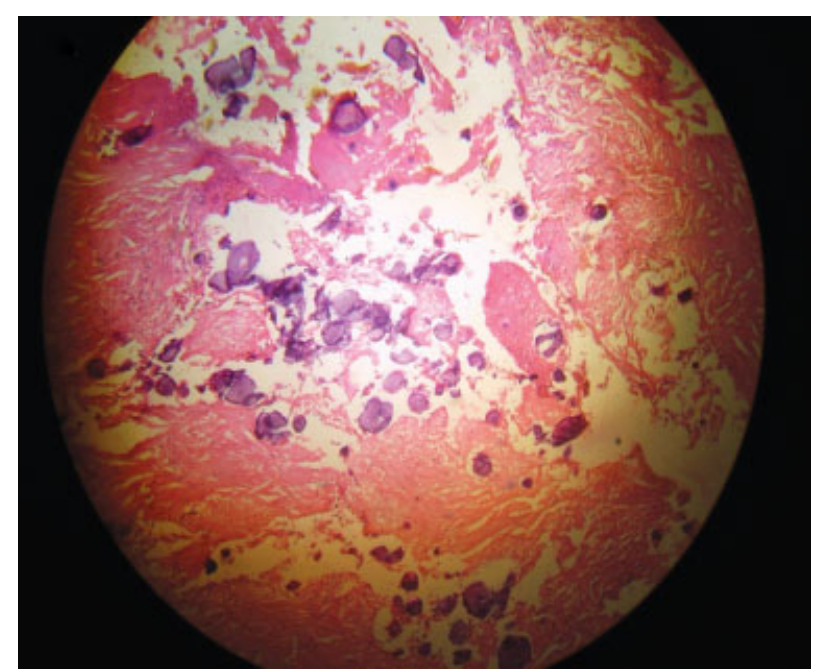

Fig. 8 Histopathological photomicrograph of an ligamentum flavum specimen showing fibro collagenous tissue (pink) produced due to elastic fiber breakdown with calcium deposits (blue; hematoxylin and eosin stain).

intracellular calcium $(\mathrm{Ca})^{28}$ and could stimulate the activation and proliferation of osteoblast-like cells with enhanced expression of mRNA and the proteins c-fos and $\mathrm{c}^{-j u n}{ }^{26}$ The retention of $\mathrm{Ca}$ in chondrocytes caused by $\mathrm{F}$ leads to degeneration and necrosis of chondrocytes followed by chondral matrix calcification and enchondral ossification. These findings suggest that $\mathrm{Ca}$ and $\mathrm{F}$ might play an important role in pathogenesis of $\mathrm{OLF}^{29}$ In our study, one characteristic finding noted in fluorosis-induced OLF was involvement of large number of spinal segments.

The symptoms of OLF are secondary to stenosis of the spinal canal. The most common clinical presentation consists of progressive thoracic myelopathy, resulting in spastic paraparesis, with or without sphincter dysfunction. Walking impairment is generally reported as the main complaint. OLF can also lead to loss of balance due to posterior column dysfunction., 5 Sensory, bladder, and bowel involvement are not rare in the later stage. ${ }^{30}$

Before the early 1990s when MR imaging was not commonly used for neurological diagnosis, myelography was considered the best diagnostic tool to detect OLFinduced thoracic cord compression. In our study also, myelogram was performed in initial period. Myelography demonstrates the level and posterior location of the compressive lesion but not its nature. Axial CT scan reveals the contour and density of ossificatory change in ligamentum flavum. A CT classification of OLF has been devised by Sato et $\mathrm{al}^{31}$ dividing the OLF into five (lateral, extended, enlarged, fused, and tuberous) types (-Fig. 6a-d). The T2-weighted sagittal imaging by MRI is modality of choice for the screening of the longitudinal extent of OLF. On MR imaging, OLF can be recognized by the presence of a triangular or hemispheric area of low signal intensity on T1- and T2-weighted images in the posterior margin of the canal. ${ }^{32}$ (- Table 4 ; - Figs. 4, 5) OLF has been "missed" on MR and later diagnosed by CT at some instances, ${ }^{5,33}$ (as the null signal of ossification can be difficult to detect on MR imaging, unlike hyperdense ossified lesion detected on CT imaging). It is therefore useful to combine CT and MR images.

Conservative treatment is not effective in preventing disease progression and neurological deterioration. Choice of a surgical procedure may be guided by type of ligamental ossification. Although several techniques have been used such as laminoplasty, ${ }^{13}$ foraminotomy, ${ }^{34}$ image-guided laminotomy, ${ }^{35}$ enblock resection, ${ }^{36}$ and laminectomy with fusion. ${ }^{17}$ But due to advanced nature of disease at presentation (as indicated by clinical symptoms/involvement of dura in large [58\%] number of our patients) we recommend that laminectomy and complete resection of the OLF is the treatment of choice. There are other reports in literature about using such method. $6,37,38$ We routinely perform decompressive laminectomy along with medial one-third facetectomy and resection of the OLF. The results show that this type of surgical method did not affect the stability of the spine in patients with OLF and no additional internal fixation and bone grafting was required. Despite good posterior decompression of thoracic myelopathy due to OLF, recovery varies widely from 25 to $100 \%{ }^{39}$ We had improvement in over $90 \%$ of our patients at their respective last follow-up.

Several peri- and postoperative complications have been reported in patients with OLF-related myelopathy. ${ }^{23}$ CSF leakage following disruption of dura is one of the major intraoperative complications. In this series, 68 (47.5\%) patients had a tear of dura mater, which was repaired. Therefore, intraoperative manipulation should be gentle to avoid duramater injury as much as possible, and once a dural tear is noticed, immediate repair should be performed. Calcification of duramater was present in 83 (58.04\%) of our patients, indicating the advanced disease at presentation. One patient also had intradural calcification. Postoperative CSF leak was observed in 11 of our patients (8.39\%) and 7 (4.89\%) had localized infection which were managed conservatively with satisfactory outcome.

Neurological deterioration can occur immediately after surgery because of unintended intraoperative spinal cord manipulation. Severe OLF results in spinal stenosis and maximum cord compression. So, no instrument should be negotiated inside the spinal canal that can cause irreversible spinal cord injury. High speed electric or pneumatic drills, followed by thin footplate rongeurs $(1 \mathrm{~mm})$ should be used to avoid this complication. Epidural hematoma is another complication that can cause postoperative spinal cord compression and induce symptom aggravation. ${ }^{15}$ No postoperative epidural hematoma occurred in our series. Some authors raise concern about increased spinal kyphotic deformity after laminectomy that can cause late-onset neurological deterioration or localized back pain. ${ }^{15}$ We have not encountered any patient developing kyphotic deformity with long laminectomy even after years of follow-up.

We found short duration of symptoms and preoperative neurological status as the most important factors predictive of outcome of statistical significance. (-Table 5) Under chronic compression the spinal cord exhibits destructive changes believed to cause motor paresis: these include 
infarction, ischemic necrosis, and neuronal loss or chromatolysis in gray matter as well as demyelination in white matter and in posterior and lateral white columns. ${ }^{30}$ It has been observed that apoptosis precedes the destructive changes in a spinal cord which is under chronic compression, resulting in profound and irreversible neuronal degeneration in posterolateral long tracts. ${ }^{40}$ This might explain the persistence of residual spasticity at the followup, due to irreversible changes within cord by thecal compression. Delay between onset of initial symptoms and surgical decompression is believed to worsen these changes. ${ }^{30}$ In other words, the short duration of symptoms, preoperatively, is a positive predictor of outcome. ${ }^{41}$

A recent study evaluating the effect of intramedullary signal changes on recovery suggested that the presence or absence of signal changes did not correlate with postoperative recovery; but whenever present, intramedullary signal size (ISS) greater than $15 \mathrm{~mm}$ significantly compromised recovery. ${ }^{39}$ The results of our study match with other studies ${ }^{39,42}$; however, we did not evaluate the effect of ISS with recovery.

\section{Conclusion}

The pathogenesis of thoracic OLF is mainly due to localized mechanical stress on the ligament and patients with fluorosis can have extensive disease. MRI is the investigation of choice as it helps in screening the longitudinal extent of disease and the cord compression. CT helps in identifying the type of OLF and type/extent of surgical resection. Wide laminectomy with excision of OLF and calcified dura is the treatment of choice. OLF is a rare cause for thoracic myelopathy and the surgical excision is the only treatment modality for it.

\section{Acknowledgment}

The work pertaining to this study was conducted at Department of Neurosurgery, Sawai Man Singh Medical College, Jaipur, India.

\section{References}

1 Jaisuresh K, Kumar VP, Sundaravadivelu V. Thoracic myelopathy due to ossified hypertrophied ligamentum flavum. Calicut Medical J 2007;5(5):e1

2 Jayakumar PN, Devi BI, Bhat DI, Das BS. Thoracic cord compression due to ossified hypertrophied ligamentum flavum. Neurol India 2002;50(3):286-289

3 Mohindra S, Chhabra R, Mukherjee KK, Gupta SK, Vaiphei K, Khosla VK. Spinal compression due to ossified yellow ligament: a short series of 5 patients and literature review. Surg Neurol 2006; 65(4):377-384, discussion 384

4 Singh P, Kar AM, Garg RK. Calcification of the thoracic ligamentum flavum: a rare cause of myelopathy. J Assoc Physicians India 2001; 49:843-844

5 Trivedi P, Behari S, Paul L, Banerji D, Jain VK, Chhabra DK. Thoracic myelopathy secondary to ossified ligamentum flavum. Acta Neurochir (Wien) 2001;143(8):775-782

6 Ben Hamouda K, Jemel H, Haouet S, Khaldi M. Thoracic myelopathy caused by ossification of the ligamentum flavum: a report of 18 cases. J Neurosurg 2003;99(2, Suppl):157-161
7 Kruse JJ, Awasthi D, Harris M, Waguespack A. Ossification of the ligamentum flavum as a cause of myelopathy in North America: report of three cases. J Spinal Disord 2000;13(1):22-25

8 Pascal-Moussellard H, Cabre P, Smadja D, Catonné Y. Symptomatic ossification of the ligamentum flavum: a clinical series from the French Antilles. Spine 2005;30(14):E400-E405

9 Xu R, Sciubba DM, Gokaslan ZL, Bydon A. Ossification of the ligamentum flavum in a Caucasian man. J Neurosurg Spine 2008; 9(5):427-437

10 Nurick S. The pathogenesis of the spinal cord disorder associated with cervical spondylosis. Brain 1972;95(1):87-100

11 Coulier B, Ghosez JP, Mailleux P. Computed tomography diagnosis of symptomatic ossification of the thoracic flaval ligaments [in French]. JBR-BTR 1998;81(3):137-140

12 Li KK, Chung OM, Chang YP, So YC. Myelopathy caused by ossification of ligamentum flavum. Spine 2002;27(12):E308-E312

13 Okada K, Oka S, Tohge K, Ono K, Yonenobu K, Hosoya T. Thoracic myelopathy caused by ossification of the ligamentum flavum. Clinicopathologic study and surgical treatment. Spine 1991; 16(3):280-287

14 Hasue M, Kikuchi S, Fujiwara M, et al. Roentgenographic analysis of ossification of the spinal ligament with special reference to the finding of the whole spine. Seikei Geka 1980;31:1179-1186

15 Aizawa T, Sato T, Sasaki H, Kusakabe T, Morozumi N, Kokubun S. Thoracic myelopathy caused by ossification of the ligamentum flavum: clinical features and surgical results in the Japanese population. J Neurosurg Spine 2006;5(6):514-519

16 Inamasu J, Guiot BH. A review of factors predictive of surgical outcome for ossification of the ligamentum flavum of the thoracic spine. J Neurosurg Spine 2006;5(2):133-139

17 Li F, Chen Q, Xu K. Surgical treatment of 40 patients with thoracic ossification of the ligamentum flavum. J Neurosurg Spine 2006; 4(3):191-197

18 Maigne JY, Ayral X, Guérin-Surville H. Frequency and size of ossifications in the caudal attachments of the ligamentum flavum of the thoracic spine. Role of rotatory strains in their development. An anatomic study of 121 spines. Surg Radiol Anat 1992;14(2):119-124

19 Miyamoto S, Yonenobu K, Ono K. Elevated plasma fibronectin concentrations in patients with ossification of the posterior longitudinal ligament and ossification of the ligamentum flavum. Spine 1993;18(15):2267-2270

20 Hayashi K, Ishidou Y, Yonemori K, et al. Expression and localization of bone morphogenetic proteins (BMPs) and BMP receptors in ossification of the ligamentum flavum. Bone 1997;21(1):23-30

21 Park JB, Chang H, Lee JK. Quantitative analysis of transforming growth factor-beta 1 in ligamentum flavum of lumbar spinal stenosis and disc herniation. Spine 2001;26(21):E492-E495

22 Postacchini F, Gumina S, Cinotti G, Perugia D, DeMartino C. Ligamenta flava in lumbar disc herniation and spinal stenosis. Light and electron microscopic morphology. Spine 1994;19(8): 917-922

23 Liao CC, Chen TY, Jung SM, Chen LR. Surgical experience with symptomatic thoracic ossification of the ligamentum flavum. J Neurosurg Spine 2005;2(1):34-39

24 Sharma RR, Mahapatra A, Pawar SJ, Sousa J, Lad SD, Athale SD. Spinal cord and cauda equina compression in 'DISH'. Neurol India 2001;49(2):148-152

25 Gupta RK, Agarwal P, Kumar S, Surana PK, Lal JH, Misra UK. Compressive myelopathy in fluorosis: MRI. Neuroradiology 1996; 38(4):338-342

26 Muthukumar N. Ossification of the ligamentum flavum as a result of fluorosis causing myelopathy: report of two cases. Neurosurgery 2005;56(3):E622, discussion E622

27 Takeuchi Y, Matsumoto T, Takuwa Y, et al. High incidence of obesity and elevated serum immunoreactive insulin levels in patients with paravertebral ligamentous ossification: a relationship to the development of ectopic ossification. J Bone Miner Metab 1989;7(1):17-21 
28 Wang Z, Li XD, Li MQ Wang QP. Changes in basic metabolic elements associated with the degeneration and ossification of ligamenta flava. J Spinal Cord Med 2008;31(3):279-284

29 Singh M, Susheela AK. Adenyl cyclase activity and cyclic AMP levels followin $\mathrm{F}$ - ingestion in rabbits and human subjects. Fluroide 1982;15:202-208

30 Fong SY, Wong HK. Thoracic myelopathy secondary to ligamentum flavum ossification. Ann Acad Med Singapore 2004;33(3):340-346

31 Sato T, Kokubun S, Ishii Y. Choice of operative method for ossification of ligamentum flavum based on CT findings [in Japanese]. Rinsho Seikei Geka 1996;31:541-545

32 Sugimura H, Kakitsubata Y, Suzuki Y, et al. MRI of ossification of ligamentum flavum. J Comput Assist Tomogr 1992;16(1): 73-76

33 Otani K, Yoshida M, Fujii E, Nakai S, Shibasaki K. Thoracic disc herniation. Surgical treatment in 23 patients. Spine 1988;13(11): 1262-1267

34 Nishiura I, Isozumi T, Nishihara K, Handa H, Koyama T. Surgical approach to ossification of the thoracic yellow ligament. Surg Neurol 1999;51(4):368-372

35 Seichi A, Nakajima S, Takeshita K, et al. Image-guided resection for thoracic ossification of the ligamentum flavum. J Neurosurg 2003;99(1, Suppl):60-63
36 Jia LS, Chen XS, Zhou SY, Shao J, Zhu W. En bloc resection of lamina and ossified ligamentum flavum in the treatment of thoracic ossification of the ligamentum flavum. Neurosurgery 2010;66(6):1181-1186

37 Miyakoshi N, Shimada Y, Suzuki T, et al. Factors related to longterm outcome after decompressive surgery for ossification of the ligamentum flavum of the thoracic spine. J Neurosurg 2003;99 (3, Suppl):251-256

38 Yonenobu K, Ebara S, Fujiwara K, et al. Thoracic myelopathy secondary to ossification of the spinal ligament. J Neurosurg 1987;66(4):511-518

39 Sanghvi AV, Chhabra HS, Mascarenhas AA, Mittal VK, Sangondimath GM. Thoracic myelopathy due to ossification of ligamentum flavum: a retrospective analysis of predictors of surgical outcome and factors affecting preoperative neurological status. Eur Spine J 2011;20(2):205-215

40 Yamaura I, Yone K, Nakahara S, et al. Mechanism of destructive pathologic changes in the spinal cord under chronic mechanical compression. Spine 2002;27(1):21-26

41 Kuh SU, Kim YS, Cho YE, et al. Contributing factors affecting the prognosis surgical outcome for thoracic OLF. Eur Spine J 2006; 15(4):485-491

42 Ahn DK, Lee S, Moon SH, Boo KH, Chang BK, Lee JI. Ossification of the ligamentum flavum. Asian Spine J 2014;8(1):89-96 